OPEN ACCESS

Edited by: Elena Martinez, Institute for Bioengineering of Catalonia, Spain

Reviewed by:

Dimitrios I. Zeugolis,

National University of Ireland, Ireland

Justin Lee Brown

Pennsylvania State University, USA

*Correspondence:

Aldo Leal-Egaña,

Center for Cell Engineering, Institute of Molecular, Cell and Systems Biology, University of Glasgow,

CMVLS, Joseph Black Building,

Glasgow G12 8QQ, UK

aldo.leal-egana@glasgow.ac.uk

Specialty section:

This article was submitted to Biomaterials, a section of the journal

Frontiers in Materials

Received: 23 February 2015

Paper pending published:

23 March 2015

Accepted: 15 April 2015

Published: 08 May 2015

Citation:

Ballester-Beltrán J, Biggs MJP, Dalby MJ, Salmerón-Sánchez M and

Leal-Egaña A (2015) Sensing the difference: the influence of anisotropic

cues on cell behavior.

Front. Mater. 2:39.

doi: 10.3389/fmats.2015.00039

\section{Sensing the difference: the influence of anisotropic cues on cell behavior}

\author{
José Ballester-Beltrán ${ }^{1}$, Manus J. P. Biggs ${ }^{2}$, Matthew J. Dalby ${ }^{3}$, \\ Manuel Salmerón-Sánchez ${ }^{1}$ and Aldo Leal-Egaña ${ }^{2 *}$ \\ ${ }^{1}$ Division of Biomedical Engineering, School of Engineering, University of Glasgow, Glasgow, UK, ${ }^{2}$ Network of Excellence for \\ Functional Biomaterials, National University of Ireland, Galway, Ireland, ${ }^{3}$ Institute of Molecular, Cell and Systems Biology, \\ University of Glasgow, Glasgow, UK
}

From tissue morphogenesis to homeostasis, cells continuously experience and respond to physical, chemical, and biological cues commonly presented in gradients. In this article, we focus our discussion on the importance of nano/micro topographic cues on cell activity, and the role of anisotropic milieus play on cell behavior, mostly adhesion and migration. We present the need to study physiological gradients in vitro. To do this, we review different cell migration mechanisms and how adherent cells react to the presence of complex tissue-like environments and cell-surface stimulation in 2D and 3D (e.g., ventral/dorsal anisotropy).

Keywords: surface topography, anisotropic materials, cell-biomaterial interface, cell-matrix anchorage, topographical cues

\section{Introduction}

When considering cell response to topographical cues, we initially think on classical contact guidance to grooves. This was first reported in 1911, when Harrison observed cells aligning to spider silk (Harrison, 1911). In the 1950s, Weiss and Garber termed this phenomenon contact guidance (Weiss and Garber, 1952). The field was popularized in the 1980s through a collaboration between a cell biologist, Adam Curtis, and an electronic engineer interested in miniaturization, Curtis and Wilkinson (1997), who observed that surface topography gradients can be sensed by adherent cells at the microscale and later, the nanoscale.

In this article, we will focus on the design of novel anisotropic polymeric surfaces and how different parameters influence cell fate. Then, we will review cell migration mechanisms in different environments and the influence that bi-phasic (ventral/dorsal) gradients play on cell activity in in vivo-like milieus.

\section{Anisotropic Topography and Cellular Function}

\section{Anisotropic Biomaterials}

The interplay between heterogeneity and anisotropy persists as the predominat strategy adapted by nature to optimize the function of biological materials. The former relates to the spatial variation (point to point) of the material properties, whereas the latter closely relates to the directional dependence (Ranganathan et al., 2011). Material topography, and in particular micro and nanoscale anisotropic structures, can affect cellular morphology as well as cellular behavior (Table 1) (Losert et al., 2013; Cassidy et al., 2014; Londono et al., 2014; Azeem et al., 2015). It is thus necessary to develop a fundamental understanding on the mechanistic processes induced by anisotropic structures in cell biology, in order to gain further insights into the design of biological materials. 
TABLE 1 | Topographic characteristic of several of anisotropic polymer scaffolds and their influence on cellular differentiation.

\begin{tabular}{|c|c|c|c|c|c|}
\hline Height/depth & Width & Pitch & Cell type & Differential function & Reference \\
\hline $650 \mathrm{~nm}$ & $500 \mathrm{~nm}$ & $3.0 \mu \mathrm{m}$ & $\begin{array}{l}\text { Upregulation of neuronal markers } \\
\beta \text {-Tubulin III and NeuN }\end{array}$ & Upregulation of neuronal markers $\beta$-Tubulin III & Marino et al. (2013) \\
\hline $4.0 \mu \mathrm{m}$ & $2.0 \mu \mathrm{m}$ & $4.0 \mu \mathrm{m}$ & $\begin{array}{l}\text { Primary murine neural progenitor } \\
\text { cells }\end{array}$ & Upregulation of neuronal marker TUJ1 & $\begin{array}{l}\text { Wang et al. (2012) and } \\
\text { Chua et al. (2014) }\end{array}$ \\
\hline $250 \mathrm{~nm}$ & $250 \mathrm{~nm}$ & $500 \mathrm{~nm}$ & Human embryonic stem cell line, $\mathrm{H} 1$ & Upregulation of neuronal markers MAP2 & Ankam et al. (2015) \\
\hline $2.0 \mu \mathrm{m}$ & $2.0 \mu \mathrm{m}$ & $4.0 \mu \mathrm{m}$ & Murine neural progenitor cells & Upregulation of neuronal markers TH, MAP2, and PITX3 & Tan et al. (2015) \\
\hline $625 \mathrm{~nm}$ & $1500 \mathrm{~nm}$ & $3 \mu \mathrm{m}$ & Human neural stem cells & $\begin{array}{l}\text { Upregulation of neuronal Tuj1 and MAP2 and glial } \\
\text { markers GFAP, O4, and Olig2 }\end{array}$ & Yang et al. (2014) \\
\hline $150 \mathrm{~nm}$ & $250 \mathrm{~nm}$ & $500 \mathrm{~nm}$ & Human MSC & $\begin{array}{l}\text { Upregulation of fibro/superficial zone cartilage formation } \\
\text { markers PRG4 and COL1 }\end{array}$ & Wu et al. (2014) \\
\hline $200 \mathrm{~nm}$ & $415 \mathrm{~nm}$ & $830 \mathrm{~nm}$ & Human MSC & No upregulation in the osteospecific marker ALP & Janson et al. (2014) \\
\hline
\end{tabular}

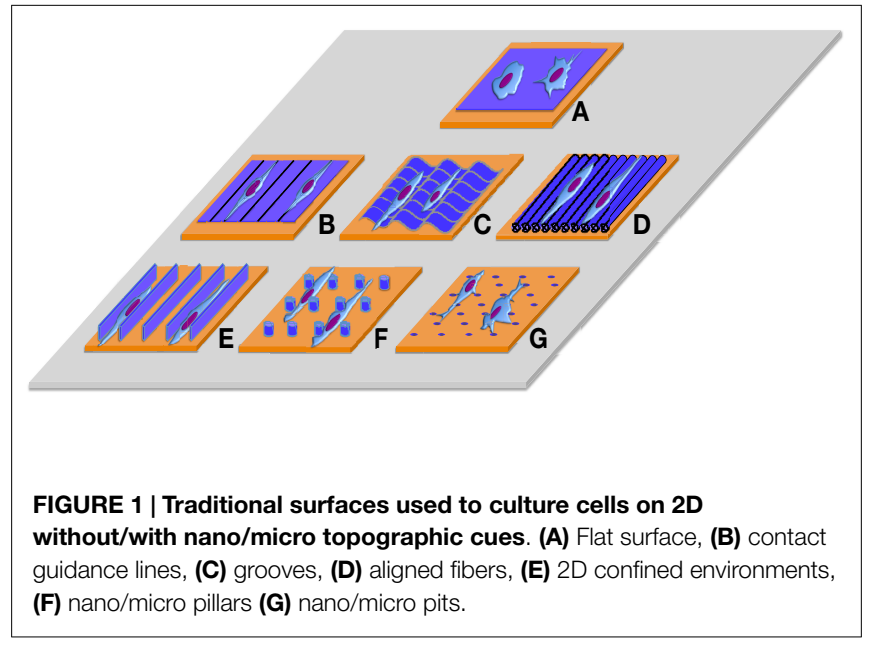

Novel techniques of nanofabrication and material processing, such as lithographic (Diehl et al., 2005; Zhu et al., 2005; Dalby et al., 2006; Smith et al., 2014) self-assembly (Tsai et al., 2014), electrospinning (Gaharwar et al., 2014), and scratching techniques (Peng et al., 2010; Wang et al., 2013a), offer the ability to create anisotropic substrates with feature widths and depths ranging from the macroscale to the microscale down to features sizes as small as $5 \mathrm{~nm}$, facilitating the aquisition of information to help understand this field (Peng et al., 2010; Wang et al., 2013a) (Figure 1). These techniques are particularly suited for the generation of anisotropic micro-nanofeatures in polymeric formulations and in particular in thermoplastics. However, with specific reference to loadbearing biomaterials, the topographical modification of metals and their alloys has received much attention recently and several novel techniques including electrical anodization (Xie et al., 2011), acid etching (Att et al., 2009), and femtosecond laser processing (Tavangar et al., 2013) have recently been described.

Both micro (Itala et al., 2003; Germanier et al., 2006; HerreroCliment et al., 2013) and nanoscale (Biggs et al., 2008; Cassidy et al., 2014; Azeem et al., 2015) groove/ridge topographies are well documented as powerful modulators of contact guidance, being relevant in tissue engineering and biomaterials manufacture. A principal design tenet of anisotropic grating substrates is that of biomimetic extracellular matrix (ECM) design, attempting to mimic the topographical structures imparted by several fibrous components of the ECM. Collagen, being the most abundant protein in the body, encompasses individual fibril elements (e.g., with dimensions of 20-30 nm) to fibril bundles (e.g., from 15-400 $\mu \mathrm{m}$ in diameter). Key to this is that nanogroove surfaces may promote cellular polarization as well as promote aligned self-assembly of ECM components with motifs critical in cell adhesion such as fibronectin and vitronectin. Indeed, the elongated cellular morphology and alignment induced by grooved substrates may resemble the natural state of tissue resident cell populations in vivo, and studies indicate that most, if not all, cells, notably fibroblasts (Dalby et al., 2003; Garland et al., 2014), osteoblasts (Lenhert et al., 2005; Wu and Wang, 2013), neurons (Yim et al., 2007; Tonazzini et al., 2014), and MSCs (Dalby et al., 2006; McMurray et al., 2013), undergo significant morphological and functional responses to anisotropic topographies.

The extent to which groove geometry and order can influence cell function is an often overlooked consideration in designing next generation biomaterials. Studies by Tonazzini et al. (2013) show that the loss of neurite guidance is not linear with noise on microgrooved topographies, but is a threshold effect, correlating with changes in focal adhesion (FA) maturation and spatial organization. Here, the authors found that nanogratings with a controlled amount of random nanotopographical noise - or defects influenced neurite contact guidance at a threshold noise level of aproximately 40 to $50 \%$. Interestingly, a further study by Gamboa and colleagues have identified that the groove orientation does not have to be linear; rather, cell can gain spatial information from anisotropic features. Indeed, cells can cross over individual grooves when they arranged in a waveform pattern, residing both inside and outside of each wave pattern, yet aligning linearly along the long axis of the pattern (Gamboa et al., 2013).

\section{Anisotropic Topography on Cell Adhesion}

Critically, nanogroove features seem to directly influence the formation and orientation of FA in vitro (Teixeira et al., 2004), probably due to the guiding of ECM proteins. A nice example has been described in the case of fibronectin, a protein which has been shown to selectively adsorb onto the ridge/groove boundaries (De Luca et al., 2015). At present, no clear conclusions have been reached regarding the absolute dimensions required for cellular 
and FA alignment; rather, this process is cell-specific and density dependent (Clark et al., 1990). It is probable, however, that an interplay between groove width and depth regulates cellular alignment, and a recent study by Crouch et al. (2009) indicated that a grating aspect ratio (depth to width) of 0.16 was required for $95 \%$ cellular alignment. Additionally, anisotropic topographies can induce alignment of sub-cellular structures including filopodia (Fujita et al., 2009), nuclei (McKee et al., 2011), and neurite extensions (Tonazzini et al., 2013).

Recent studies indicate that FA alignment is generally more pronounced on patterns with ridge widths between 1 and $5 \mu \mathrm{m}$ than on grooves and ridged topographies with larger lateral dimensions (Biggs et al., 2008; Yang et al., 2010). Moreover, cells cultured on grooves with nanoscale widths produce FA that are non-polarized (Kim et al., 2013) or almost exclusively oriented obliquely to the topographic patterns (Teixeira et al., 2006). This occurs predominantly on topographical ridges as opposed to grooves, effectively limiting the length of FA formed perpendicular to the groove orientation. Thus, it arises that grooved nanoscale topographies can influence both the adhesion direction as well as adhesion reinforcement (Biggs et al., 2010).

\section{Anisotropic Topography and Cellular Function}

The mechanisms by which anisotropic topography and ordered protein deposition influence cellular proliferation and differentiation require more research. Anisotropic arrays of topographical micro and nanoscale gratings have been shown to be potent tools in maintaining the phenotype of primary cells (Zhu et al., 2010) and in differentiating stem cells toward expressing osteogenic (Dalby et al., 2007; Biggs et al., 2009a; Watari et al., 2012), tenogenic (Wojciak et al., 1995), neurogenic (Jeon et al., 2014), adipogenic (Wang et al., 2012), and myogenic (Wang et al., 2013b) transcripts and proteins. The processes that mediate the cellular reaction to anisotropic surface structures, however, are not well understood and may be direct (Cassidy et al., 2014) or indirect (where the surface structure has affected the composition, orientation, or conformation of the adsorbed ECM components)(PerezGarnes et al., 2011; Ballester-Beltran et al., 2012a).

Multiple studies with mesenchymal stem cell populations point toward the negative effects of micronscale grooves and pronounced cell polarization on osteospecific differentiation (Biggs et al., 2008; Watari et al., 2012), a process appearing to be more influenced by sub $500 \mathrm{~nm}$ topographies. Conversely, more adipospecific (Wang et al., 2012) and myogenic (Wang et al., 2013b) differentiation is demonstrated to be enhanced by polarization through micronscale grooved topographies. Periodicity has also been shown to be important in modulating differential function in pluripotent cells. In particular, if mesenchymal stem cells are cultured on grooves with a short feature pitch and become highly aligned, this reduces osteogenesis. However, if the pitch is increased so the grooves are more step cues (around $50 \mu \mathrm{m}$ pitch), then osteogenesis is achieved with great efficiency (Biggs et al., 2009b).

The mechanism by which anisotropic grating surfaces influence cell function, however, is still being resolved; multiple studies suggest that cells cultured on topographical gratings modulate transcriptional events through adhesion-dependent phosphorylation of downstream signaling molecules (e.g., mediated FA kinases, FAK) (Figure 2A). FA pathway signaling has been shown to control essential cellular processes such as growth, survival, migration, and differentiation. Interestingly, extensive evidence has also been generated on the involvement of extracellular signal-related kinase (ERK) 1/2 down-regulation following integrin-mediated FAK activation, in response to grooved substrates (Biggs et al., 2009b; Cassidy et al., 2014).

\section{A Case of Study: Anisotropic Surfaces and Immune Activation}

Besides analyzing the influence of anisotropic features in adherent cells, it seems that these surfaces can also induce a significant response in several non-adherent cell types (Kwon et al., 2012) (e.g., cells belonging to the immune system).

Several studies have reported on the effects of nanotopographical structures on immune cell motility (Song et al., 2012) and actin rich structures (e.g., lamella and filopodia) are reported to play a significant role in this process (Song et al., 2014). Emerging data suggest that the proteins involved in adhesive processes in cells of the immune system are analogous to those found in FA in adherent cells (Hocde et al., 2009), and that leukocyte binding to ECM components and adsorbed complement proteins can induce FAK-mediated immune cell activation (Bhattacharyya et al., 1999), phagocytosis (Kasorn et al., 2009), and chemokinemediated migration (Cohen-Hillel et al., 2009). Similarly, Bartneck and colleagues reported that a microstructured topography of regular grooves induced a pro-inflammatory phenotype in macrophages, which was not accompanied by release of proinflammatory mediators (Bartneck et al., 2010).

Although the immune response is tightly regulated by the complex interplay of events and interactions between its constituent cells, preliminary studies suggest that anisotropic topographies may be employed to induce cell activation and as in adherent cell types, this may be through FAK-mediated activation of critical signaling pathways.

\section{Perspectives on Cell-Material Interactions}

The interactions between cellular populations and engineered substrates are bidirectional; e.g., a mechanical cellular mediated deformation of the scaffold modulates the physical environmental properties. Consequently, in order to better understand the dynamic nature of topographical mediated direction of cellular function stimuli, responsive or "smart" materials are increasingly being employed in cell studies. New reports demonstrate that mechanically active anisotropic topographies can yield critical insight into the role of groove dimension on cellular function through dynamic modulation of the feature dimensions.

Shape memory polymers have recently been employed for this purpose and can be designed with a physiological transition temperature to provide an alternate morphology or topography when subjected to physiological temperatures (e.g., between 32 and $37^{\circ} \mathrm{C}$ ), providing dynamic mechanical cues or anti-adhesive surfaces (Ebara et al., 2014). A study by Gong et al. investigated microgroove surface patterns formed on a cross-linked poly $(\varepsilon$ caprolactone) substrate. Here, a dynamic response to cyclic temperature (e.g., between 32 and $41^{\circ} \mathrm{C}$ ) resulted in the modulation 


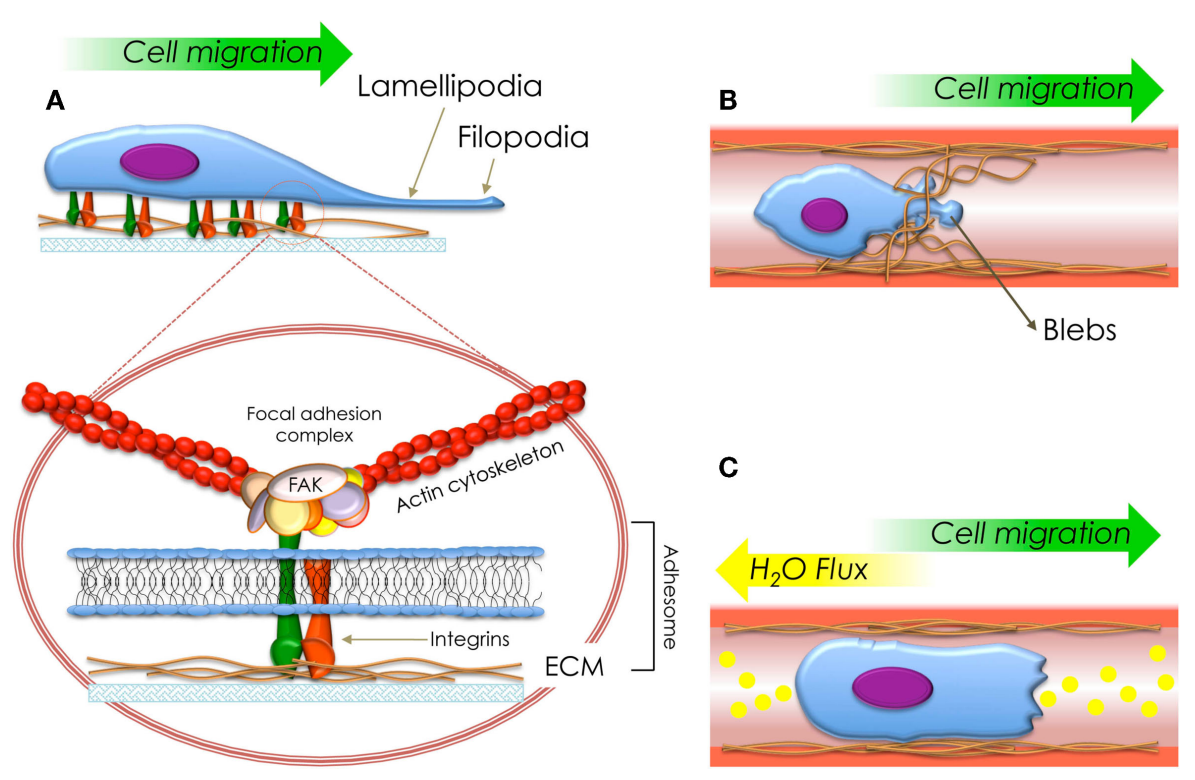

FIGURE 2 | Schematization of the types of migration fashions described in this review. (A) Cell migration mediated by the protrusion of lamellipodia (mesenchymal migration). The circle shows a detailed structure of a focal adhesion and adhesome. (B) Cell migration mediated by generation of blebs (amoeboid migration) and (C) cell migration mediated by flux of ions and water (osmotic engine model). of the microgroove dimensions, influencing cell shape and the cytoskeletal arrangement of adherent bone marrow stem cells, which upregulated myospecific genes and proteins (Gong et al., 2014).

Although a large number of studies have reported the effects of nanotopographical structures on modulations to cell function in vitro (Dalby et al., 2007; Biggs et al., 2009b), a limited number of studies in vivo have been conducted (Fernandez-Yague et al., 2014), particularly in osteointegration and de novo bone formation (Xia et al., 2012b; Svensson et al., 2013). A recent study by Yin et al. demonstrated the significant effects of anisotropy in a rat Achilles tendon repair model. Here, anisotropic scaffolds and enhanced alignment resulted in tendon regeneration, while randomly ordered isotropic scaffolds induced ectopic bone formation. Interestingly, the influence of anisotropic micro and nanotopography on osteospecific function seems to be most effectively translated to an in vivo response when applied in combination with microscale grating features, indicating a possible synergy between the cellular (micro) and subcellular (nano) in directing regeneration (Kim et al., 2014a).

Considering these indications, it appears logical to expect significant efforts to translate findings from model (e.g., polymer) surfaces into orthopedic materials such as ceramics and metals. However, these materials are hard to manufacture due to the hardness of the materials and the brittle nature of ceramics. Also, while structural orthopedic ceramics, such alumina/zirconia, tend to be highly bio-inert, metals such as titanium and its alloys are highly adhesive to cells due to their reactive oxide layers and both these low and high adhesion environments can mask topographical effects. However, recent advancements in pre-sintering embossing of green ceramics have illustrated that groove patterns in alumina with different widths can be used to influence fibrous tissue (narrow width, $20 \mu \mathrm{m}$ pitch) and hard tissue $(150 \mu \mathrm{m}$ pitch with $100 \mu \mathrm{m}$ groove $/ 50 \mu \mathrm{m}$ ridge) growth from human osteoprogenitor cells (Nadeem et al., 2013), similarly to results observed on polymers (Biggs et al., 2008).

For metals, there is plenty of literature showing potential effects on more random topographies from etching, blasting, and anodizing (Anselme et al., 2000; McNamara et al., 2011; Sjöström et al., 2012, 2013; Olivares-Navarrete et al., 2015) due to the need for fast fabrication protocols. However, Anselme et al. have indicated potential positive effects for grooves in metals (Anselme et al., 2004). We further note that other cell types have been shown to be responsive to topographies in metals - again though, roughened rather than grooved (Lee et al., 2014; Kim et al., 2015).

As we can observe, anisotropic surfaces can stimulate in vitro and in vivo cell activity. However, it is still unclear how cell adhesion can be affected by topographic cues. In the next section of this review, we will consider the best understood mechanisms for cell adhesion and migration, focusing further discussions on the influence of ventral and dorsal stimulation on adherent cells.

\section{Cell Motility}

During the last years, it has been demonstrated that cell anchorage and motility play important roles in a wide spectrum of biological processes, such as mechano and chemotaxis (Andreas et al., 2014; Charras and Sahai, 2014), as well as wound healing and tissue repair (Gattazzo et al., 2014). Furthermore, similar to tissue repair, several diseases (e.g., cancer) have evolved to use adhesion and migration as part of their pathogenic strategy (Farahani et al., 2014), making research on cell migration an extremely relevant field and showing the necessity to study this process in detail.

Since anisotropic surfaces play a potent role on cell migration, in the next section we will briefly describe different mechanisms used by migrating cells to displace into complex environments, 
putting into context topographic cues detected on 2D surfaces or 3D milieus.

\section{Cell Migration on 2D: Following the Front Cell Migration Mediated by the Protrusion of Lamellipodia}

One of the most researched migration mechanisms on flat surfaces, at the single-cell scale, corresponds to mesenchymal migration.

Mesenchymal migration is recognized by the presence, adhesion, and protrusion of lamellipodium. From the molecular point of view, this type of migration requires cell-matrix adhesion structures (e.g., protein clusters) named adhesomes, which are composed by intra-, trans-, and extra- cellular proteins (Figure 2A).

The most important mediator between cells and their milieu are heterodimer transmembrane proteins known as integrins. Integrins comprises $\alpha$ - and $\beta$ - chains. $\beta$-subunits interconnect ECM proteins (e.g., collagen, fibronectin, elastin, etc.) with the cytoskeleton (e.g., actin stress fibers), allowing the sensing of elastic and topographical properties of the milieus where they are anchored through the exertion of traction forces (Figure 2A). Cell-matrix adhesion and mechanosensing are mediated by nonreceptor tyrosine kinases, the most notable of which is FAK, a molecule constitutively associated with the $\beta$-integrin subunit. FAK is localized at adhesion structures. It promotes talin recruitment to modulate adhesion reinforcement, and further unraveling of these stimuli by intracellular kinases (e.g., FAK) bound to transmembrane integrins and linking proteins (e.g., vinculin and paxillin) (Ridley et al., 2003; Vicente-Manzanares and Horwitz, 2011; Leal-Egaña et al., 2013).

\section{Adhesion Structures and Cell Polarization}

Mesenchymal migration is a cyclic process defined by cell polarization (Ridley et al., 2003). The first step consists in the protrusion of the membrane in the direction of migration. Two different types of protrusion have been identified: lamellipodia (large and broad) and filopodia (spike-like). In both cases, they are driven by actin polymerization and stabilized by their adherence to ECM proteins.

Differences in function have been observed between these protrusions: while filopodia are constituted by parallel actin fibers and are well designed to serve as "sensors" and explore the environment, lamellipodia are constituted by branched actin capable of supporting traction forces involved in cell displacement.

After generation of mature adhesions at the lamellipodia in the cell edge, traction forces generated by the actomyosin network pull the cell body in the direction of the lamellipodia, producing the unidirectional displacement of the cell. During this process, the Arp 2/3 complex plays a preponderant role, inducing actin polymerization at the lamellipodia and generating dendritic actin networks (branches) with pre-existing filaments at the cell front. This polarization defines the final direction of the migration. Simultaneously, during the translocation of the cell body, the Arp $2 / 3$ complex is inhibited at the trailing edge of the cells, inducing detachment of adhesomes and release of the rear part of the cells from the substrate (Vicente-Manzanares and Horwitz, 2011; Hanein and Horwitz, 2012).
Adhesomes attachment/detachment and cell polarization are regulated by two families of GTPases with antagonistic activity and localization in the cell: Rho and Rac. While Rho proteins activate actin polymerization, promote cell adhesion, and generate a leading edge due to their interaction with the Arp 2/3 complex; Rac GTPases produce the disassembly of the actin fibers and the detaching of integrins from ECM proteins, as observed at the trailing edge (Vicente-Manzanares and Horwitz, 2011; Petrie and Yamada, 2012).

Finally, it is important to indicate that, even though it seems that the biological machinery involved in cell migration could also be related to the sense of topographic cues, there is not clear information about the mechanisms by which cells can sense differences in structure and geometrical organization of 2D milieus during their displacement.

\section{Cell Motility Within Complex 3D Milieus}

During recent years, several biophysical mechanisms used for cells during migration have been studied, which are described in the next section of this review. These migration mechanisms, mostly observed in migrating cells within complex environments (e.g., micro-channels, filamentous 3D milieus), can give us clues about the way cells could interact with topographic cues found in $3 \mathrm{D}$ milieu.

\section{Cell Migration Mediated by the Protrusion of Lobopodia}

When cells migrate within 3D elastic environments, a special type of protrusion, named lobopodia, can be observed. Lobopodia are mostly represented as non-sharp cylindrical protrusions that might be driven by intracellular pressure rather than actin polymerization (Petrie and Yamada, 2012). Moreover, and although it has been shown that lobopodia contraction is mediated by RhoAROCK-myosin II signaling, this type of migration still remains less understood and poorly characterized (Petrie et al., 2014).

With respect to lobopodia, there is little information about structure and composition, although it has been proposed that the myosin IIa acts through vimentin filaments (polarized to the anterior of lobopodial cells and anchored to the nucleus, likely by nesprin-3) easing cell migration (DeSimone and Horwitz, 2014). Particularly, Petrie et al. (2014) suggests that the nucleus physically divides the cell in two compartments, maintaining differences in hydrostatic pressure between the leading and the rear parts of the cell.

\section{Cell Migration Mediated by Generation of Blebs}

Displacement through plasma membrane blebbing is one of the simplest biological mechanisms used by migrating cells (Charras and Paluch, 2008; Fackler and Grosse, 2008). Traditionally named amoeboid migration, this process is characterized by the formation of spherical membrane protrusions (e.g., blebs) (Figure 2B), produced by contraction of the actomyosin cortex. This phenomena is dependant on cortical tension and the integrity of actin cortex (Charras and Paluch, 2008).

From the molecular point of view, amoeboid migration is dependent on the activity of Rho GTPase and actomyosin contractility. However, it is noteworthy to remark that, differently to 
mesenchymal migration, the blebbing mechanism generates low traction forces since the Arp 2/3 complex is not required (Bergert et al., 2012). As bleb motility requires less energy than mesenchymal cell translocation, this mechanism has been mostly studied on metastatic cells, due to their capacity to escape from antitumor treatments based on protease inhibitors, or during their speedy migration onto low adherent surfaces and/or confined environments.

It is important to indicate that, although several cancers exhibit only one migration style, several cancer lines can easily switch from mesenchymal to amoeboid displacement when they are embedded within three-dimensional (3D) matrices (Bergert et al., 2012; Paluch and Raz, 2013). Moreover, Bergert and colleagues demonstrated that when the Arp 2/3 complex is inhibited (e.g., by using the compound CK-666 in Walker cells cultured on $2 \mathrm{D}$ surfaces), lamellipodia are replaced by bleb formation, probably by controlling the actin cortex and/or cortical tension (Bergert et al., 2012).

However, it is important to indicate that even though current research has demonstrated the use of blebs as a mechanism for cell migration, there is a lack of information concerning the mechanisms involved in translocation and forces implied in cell movement (Charras and Paluch, 2008; Paluch and Raz, 2013). Then, and although it is still unclear, the mechanisms by which cells translocate themselves using blebs appear related to periodicity in the formation of protrusions and the regular generation of small pseudopodia on the leading edge allowing the translocation of the cytosol and intracellular organelles through them (Charras and Paluch, 2008; Paluch and Raz, 2013).

It is important to indicate that, although migration mediated by blebs have been mostly studied on scaffolds exhibiting topographic cues (e.g., micro channels, fibrous matrices), there is no information regarding the influence that these topographic cues play on cell migration. However, and as was previously noted, first attempts to solve this question have been focused on immune-cells exhibiting an amoeboid migration fashion.

\section{Cell Migration Mediated by Flux of lons and Water}

Recently, Stroka and colleagues demonstrated in vitro that neoplastic cells migrating in confined $3 \mathrm{D}$ matrices use an actin/myosin-independent mechanism based on the permeation of ions and water through trans-membrane channels (Figure 2C). This new translocation strategy, named the osmotic engine model (Papadopoulos and Saadoun, 2014; Stroka et al., 2014a), can explain cell displacement within 3D environments (e.g., $3 \mu \mathrm{m}$ wide channels) in the presence of myosin, Rho/Rock kinase, and/or $\beta 1$ integrin inhibitors (Balzer et al., 2012; Stroka et al., 2014b).

Although this process is currently under study, mathematical and biochemical analysis have revealed that this type of migration requires the coordinated activity of polarized ion channels and aquaporins, which modulate fluxes of ions and water from the leading (flux in) to the trailing edge (flux out), where the sodium hydrogen exchanger-1 (NHE-1) and aquaporin 5 (AQP5) -recruited by cortical actin polymerization - seem to play a preponderant role on cell motility and regulation of intracellular $\mathrm{pH}$ (Stroka et al., 2014a,b).

\section{Role of the Nucleus on Cell Migration Within 3D Milieus}

The nucleus is the largest and stiffest organelle in cells. Since cell migration within $3 \mathrm{D}$ matrices is restricted by the pore cutoff/size distribution, cells need to squeeze the nucleus through via myosin-II mediated contraction (Friedl et al., 2011).

During the lobopodia-based migration, via the actomyosin contractility, the nucleus acts as a piston pressurizing the leading compartment. This results in bleb formation, lobopodia formation, and protrusion, and finally cell migration. Recently, Petri and colleagues compared the intracellular hydrostatic pressure in front of the nucleus, for cells cultured on/in 2D and 3D environments, finding differences of approximately 10 -fold between these two systems (from approximately 300 to $700 \mathrm{~Pa}$ in lamellipodia compared to approximately $2200 \mathrm{~Pa}$ in lobopodia). According to the authors, when cells are confined within defined 3D micro channels (approximately $20 \mu \mathrm{m}$ diameter), the nucleus compartmentalize the intracellular volume, this then acts as a piston, which enhances the hydrostatic pressures at the frontal edge of the cell with respect to the rear edge (approximately 2400 vs. $900 \mathrm{~Pa}$ ). This results in bleb formation, lobopodia formation, and protrusion, and finally cell migration. Molecularly, the actomyosinvimentin-nesprin-3 complex (e.g., intermediate filaments) seems to be responsible for pulling the nuclei to the front of the cell, and its influence on the cell displacement within 3D channels (Petrie et al., 2014).

\section{Cell Migration on Nano/Micro Topographic Designed Environments}

It is known that cells can switch spontaneously between different migration mechanisms after remodeling cytoskeleton arrangement depending on their environment. Thus, in vitro and in vivo gradients may lead to changes in cell migration among other important cellular processes. In almost all cases, the migration fashion will be dependent on the balance between actin polymerization, rear contractility, and adhesion. First attempts to explain this behavior have been done in 3D micro-channels after analysis of actin organization at the leading edge. According to the authors, there are two different F-actin networks involved in cell sensing and migration: one polymerizing at the cell-matrix interface (Wilson et al., 2013) and a "free" fragment growing on the leading edge. Both structures can communicate and interact mechanically (Wilson et al., 2013), suggesting that cytoskeleton, compartmentalization, and hydrostatic pressures produced by the nucleus as well as sensing of topographic characteristics of the cell milieu by migrating cells are intimately related. However, as was previously discussed, the biological mechanism by which cells recognize topographic cues, and their influence on cell migration, is still far away for being explained.

\section{Physiological Gradients and Bi-Phasic Biophysical Stimulation}

Traditionally, cell culture has been performed on 2D substrates where cells sense and respond to ventral stimulation (e.g., topographical cues). However, standard flat surfaces differ from in vivo milieus, where cells are subjected to complex $3 \mathrm{D}$ gradients, 


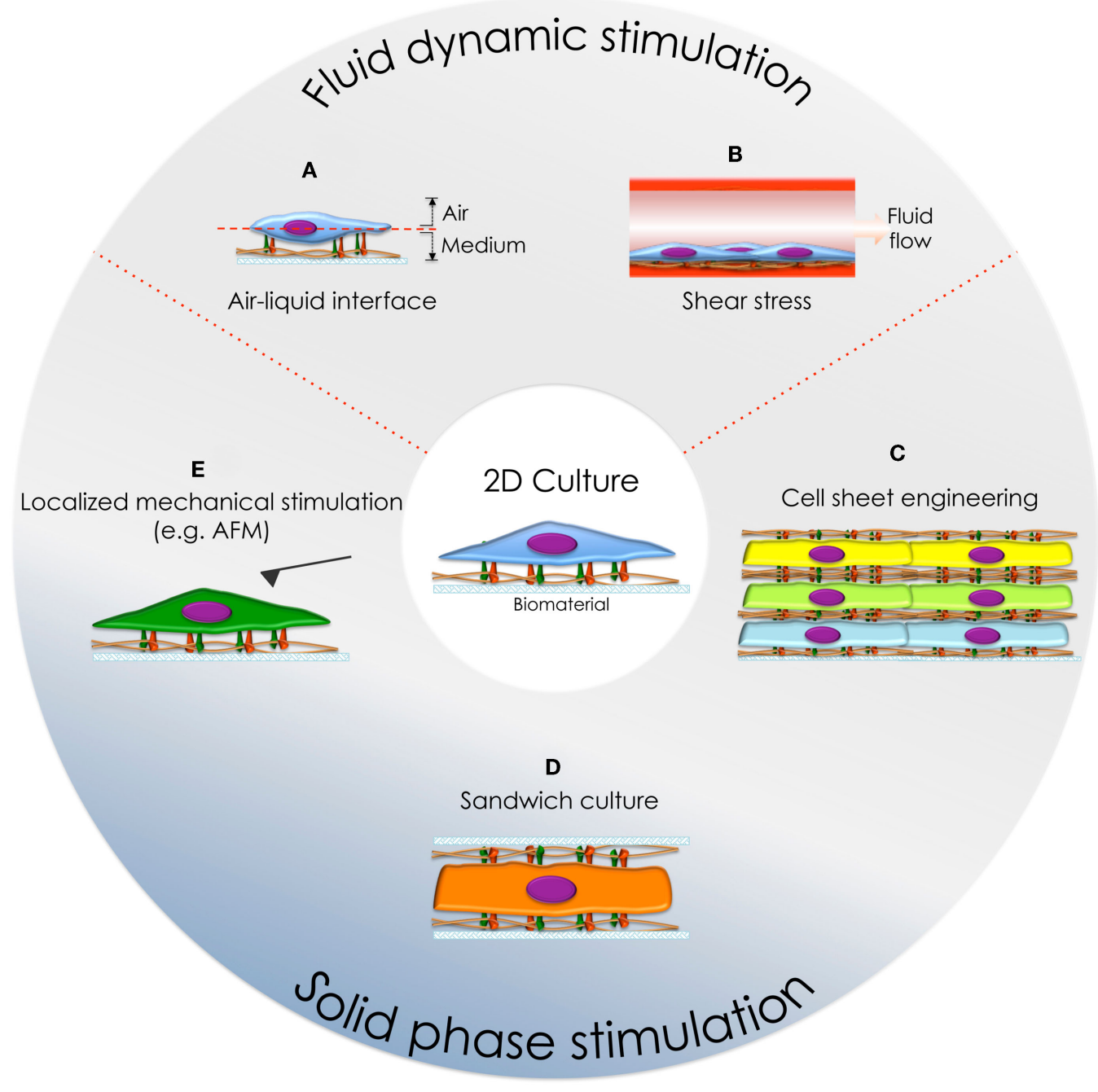

FIGURE 3 | Cell culture systems developed to mimic the physiological environment in vitro. (A) Air-liquid interface culture and (B) cell culture under fluid flow conditions. (C) Cell-sheet engineering, (D) sandwich culture, and (E) localized dorsal stimulation using an AFM cantilever.

such as differential ventral/dorsal exposure to liquid-gas phases (e.g., lungs), shear stress produced by fluid flow (e.g., endothelial tissues), or surrounded by an ECM (e.g., parenchymal tissues) (Figure 3).

These complex environmental stimuli have been reconstituted in vitro, with the purpose to study cell behavior in physiologicallike conditions. Here, we will focus on the simultaneous ventral/dorsal stimulation of cells, seeking to recapitulate the physiological cell behavior.

\section{Fluid Dynamic Stimulation}

This type of stimulation can be divided in two groups, according to the physical sub-phase involved in cellular stimulation:

\section{Liquid-Gas Phase Stimulation}

The epithelium is a polarized tissue where cells are ventrally anchored to the ECM and dorsally contacting a gas phase. Thus, fully immersed epithelial cells cultures (e.g., traditional culture strategy on 2D substrates) differ from the physiological environment. Consequently, alternative methods allowing dorsal contact to a gas phase have been developed (e.g., roller bottles, rocking platforms, and inverted cultures) (Voisin et al., 1977).

Nowadays, the use of the air-liquid interface culture (ALI, Figure 3A) has become a traditional system used to cultivate epithelial cells because it resembles the physiological condition (Voisin et al., 1977; Zamora et al., 1983, 1986; De Borja Callejas et al., 2014) and thus makes possible to perform drug testing, among other analysis, in physiologically relevant environments (Kooter et al., 2013; Kim et al., 2014b; Ashraf et al., 2015).

\section{Dynamic Fluid Flow Stimulation}

Blood vessels are internally covered by endothelial cells, exposing their ventral surfaces to parenquimal tissues (e.g., ECM), and dorsally to the lumen of the vessels: being stimulated by forces produced by fluid displacement (e.g., shear stress). Therefore, new in vitro culture systems providing constant flow or even pulsatile stress have been performed (Table 2; Figure 3B). 
TABLE 2 | Effect of fluid flow on different cell lineages.

\begin{tabular}{|c|c|c|}
\hline Cell type & Effect of fluid flow & Reference \\
\hline Endothelial cells & $\begin{array}{l}\text { Cell alignment } \\
\text { Release of vaso-active substances (e.g., endothelin-1) and nitric oxide synthase }\end{array}$ & $\begin{array}{l}\text { Ishibazawa et al. (2011) } \\
\text { and Vozzi et al. (2014) }\end{array}$ \\
\hline Vascular smooth muscle cells & $\begin{array}{l}\text { Decrease cell proliferation } \\
\text { Increase NO production } \\
\text { Increase of fibroblast growth factor (FGF)-2 production }\end{array}$ & $\begin{array}{l}\text { Papadaki et al. (1998) and } \\
\text { Lindner et al. (1991) }\end{array}$ \\
\hline Osteoblast cells & $\begin{array}{l}\text { Induction of } \mathrm{NO} \text { and prostaglandin E2 production } \\
\text { Activation of growth factor signaling pathways } \\
\text { Alteration in the Wnt/ } \beta \text {-catenin and bone formation signaling pathway }\end{array}$ & $\begin{array}{l}\text { Smalt et al. (1997) and Jia } \\
\text { et al. (2014) }\end{array}$ \\
\hline Stem cells & $\begin{array}{l}\text { Cell alignment } \\
\text { Increase in the angiogenic and vasculogenic potential of endothelial cells derived } \\
\text { from human embryonic stem cells (hESC) } \\
\text { Positive modulation of the stem cell proliferation and differentiation }\end{array}$ & $\begin{array}{l}\text { Metallo et al. (2008), } \\
\text { Huang et al. (2005), Lim } \\
\text { et al. (2013), and Potter } \\
\text { et al. (2014) }\end{array}$ \\
\hline
\end{tabular}

It is now well characterized that the excitation of the dorsal receptors stimulates protein kinase $\mathrm{C}$ (PKC) and the mitogenactivated protein (MAP) kinase pathways, resulting in gene transcription modulation and control of e.g., endothelial growth and vaso-active substances secretion such as endothelin-1 and endothelial nitric oxide synthase-3 (Vozzi et al., 2014).

The influence of shear stress has also been studied on additional cell lineages, such as vascular smooth muscle cells, since these can be encounter in endothelium-desquamated injuries and are therefore involved in the response to vascular wounds. Furthermore, the effect on osteocytes has been studied, since the fluid flow over the osteocyte network has been suggested to be the main cellular signal-generating factor (e.g., as a result of mechanical loading of bone) (Piekarski and Munro, 1977; Cowin and Weinbaum, 1998; Knothe Tate et al., 1998, 2000) (Table 2).

\section{Solid Phase Stimulation}

Cells embed within 3D milieus are subjected to physical (e.g., stiffness and pores), chemical (e.g., cytokines and growth factors), and biological (e.g., cell-cell contact and cell-ECM adhesion) gradients during tissue morphogenesis and homeostasis. Among the strategies developed to recreate this environment, hydrogels represent a convenient and well-studied system due to their structural and compositional similarities to natural ECM and the advances in material chemistry that allow tunable physical, chemical, and functional properties (Sant et al., 2010; Pedron et al., 2015).

Here, we will focus on cell culture systems that trigger bi-phasic adhesion signaling such as, sandwich culture, cell sheet engineering, and dorsal stimulation [e.g., by atomic force microscopy (AFM)] (Figures 3C-E, respectively) (Takahashi et al., 2013). In these systems, even if cells are not completely embedded within a 3D matrix, the stimulation of dorsal cell receptors triggers cell adhesion and specific signaling pathways that determine cell fate as a balance between ventral and dorsal stimulation.

Sandwich cultures involve confining cells within two substrates - dorsally and ventrally - with the same or different properties. One of the best known examples are collagen constructs, used preferentially in culture of hepatocytes since these cells lose their metabolic functions when attached to $2 \mathrm{D}$ substrates. However, the use of sandwich cultures made of ECM proteins (e.g., collagen on the top and the bottom), allow hepatocytes to maintain their polarization and metabolic activity (e.g., albumin, urea, transferrin, fibrinogen, and bile salt secretion, as well as cytochrome activity (P450 activity) restored (Swift et al., 2010 and Dunn et al., 1992, respectively). Furthermore, this type of culture allows hepatocytes to generate bile canalicular networks (Bi et al., 2006). Thus, this system is a very straightforward tool to study in vitro hepatocellular function, such as protein synthesis and/or drug metabolism (Xia et al., 2009, 2012a).

Cell-sheet engineering techniques are based in stacking 2D cell layers, including the underlying ECM, to generate a 3D tissue that consists of alternate layers of cells and ECM. The technique enables the study of more complex environments, mimicking the multidimensional organization of some tissues and organs. This system stresses the key role of dorsal stimulation for hepatocyte cultures and shows that the $3 \mathrm{D}$ coculture of hepatocyte and endothelial cells results in a powerful tool to gain more comprehensive knowledge of liver metabolism, detoxification, and signaling pathways in vitro (Harimoto et al., 2002; Kim and Rajagopalan, 2010).

We, among others, have been involved in the research of new alternatives for sandwich cultures, such as the use of ventral and dorsal surfaces with different properties/characteristics (e.g., stiffness and/or topological patterns) (Ballester-Beltrán et al., 2015). This system has shown cell morphology to be related to substrate rigidity and the ability of cells to reorganize ECM proteins adsorbed to these surfaces (Beningo et al., 2004; Ballester-Beltran et al., 2012b; Ballester-Beltrán et al., 2014). Furthermore, it has been shown that sandwich-like cultures can modify cell spreading/elongation and migration rates depending on the substrates properties, resulting in closer $3 \mathrm{D}$ environment behaviors (Beningo et al., 2004; Ballester-Beltrán et al., 2015).

Cells cultured within these bi-phasic systems adhere to the ventral and dorsal substrates, exerting tensional forces on each surface (e.g., spatially tunable mechanotransduction). This was first observed when osteosarcoma U2OS cells were ventrally attached to $2 \mathrm{D}$ fibronectin-coated glass. In this configuration, cells were dorsally stimulated by AFM using a fibronectin-coated cantilever (Figure 3E). In response to this stimulus, cells adhered and spread on the cantilever forming new fibrillar actin fibers connecting both surfaces, which enabled the cells to contract and pull the cantilever (Chaudhuri et al., 2009). Hence, cell interaction mediated by dorsal stimulation triggers changes in the cytoskeleton arrangement and generates new adhesion structures. This might link 
ventral and dorsal sides, allowing a complex response to bi-phasic stimuli, such as the fact that dorsal stimulation induces modification of ventral adhesions (Fuentes et al., 2011; Ballester-Beltrán et al., 2015), indicating the existence of a clear balance between ventral and dorsal stimulation.

When aligned electrospun fibers are used to stimulate dorsal cell adhesion, cells elongate and align in the direction of the fibers. Interestingly, when sandwich-like cultures consist of aligned fibers contacting cells ventrally, and a flat surface stimulating cells dorsally, cells remain aligned to ventral fibers. These results suggest that the topographical cues play a major role irrespective of which surface they are presented to (Ballester-Beltran et al., 2013). As expected, this alignment is depending on the cell adhesion to fibers, since cells were not able to align when they were coated with non-adhesive proteins (e.g., albumin).

\section{Outlook and Conclusion}

In this review, we have shown the important role gradients have in vivo and different methods to recapitulate them in vitro. We had

\section{References}

Andreas, K., Sittinger, M., and Ringe, J. (2014). Toward in situ tissue engineering: chemokine-guided stem cell recruitment. Trends Biotechnol. 32, 483-492. doi:10. $1089 /$ scd.2005.14.329

Ankam, S., Lim, C. K., and Yim, E. K. (2015). Actomyosin contractility plays a role in MAP2 expression during nanotopography-directed neuronal differentiation of human embryonic stem cells. Biomaterials 47C, 20-28. doi:10.1016/j. biomaterials.2015.01.003

Anselme, K., Bigerelle, M., Loison, I., Noël, B., and Hardouin, P. (2004). Kinetic study of the expression of beta-catenin, actin and vinculin during osteoblastic adhesion on grooved titanium substrates. Biomed. Mater. Eng. 14, 545-556.

Anselme, K., Linez, P., Bigerelle, M., Le Maguer, D., Le Maguer, A., Hardouin, P., et al. (2000). The relative influence of the topography and chemistry of TiAl6V4 surfaces on osteoblastic cell behaviour. Biomaterials 21, 1567-1577. doi:10.1016/S0142-9612(00)00042-9

Ashraf, S., Brockman-Schneider, R., Gern, J.E. (2015). Propagation of rhinovirus$\mathrm{C}$ strains in human airway epithelial cells differentiated at air-liquid interface. Methods Mol Biol 1221, 63-70. doi:10.1007/978-1-4939-1571-2_6

Att, W., Yamada, M., and Ogawa, T. (2009). Effect of titanium surface characteristics on the behavior and function of oral fibroblasts. Int. J. Oral Maxillofac. Implants 24, 419-431. doi:10.1016/S0022-3913(10)60106-0

Azeem, A., English, A., Kumar, P., Satyam, A., Biggs, M., Jones, E., et al. (2015). The influence of anisotropic nano- to micro-topography on in vitro and in vivo osteogenesis. Nanomedicine 5, 693-711. doi:10.2217/nnm.14.218

Ballester-Beltran, J., Cantini, M., Lebourg, M., Rico, P., Moratal, D., Garcia, A. J., et al. (2012a). Effect of topological cues on material-driven fibronectin fibrillogenesis and cell differentiation. J. Mater. Sci. Mater. Med. 23, 195-204. doi:10.1007/s10856-011-4532-z

Ballester-Beltran, J., Lebourg, M., Rico, P., and Salmeron-Sanchez, M. (2012b). Dorsal and ventral stimuli in cell-material interactions: effect on cell morphology. Biointerphases 7, 39. doi:10.1007/s13758-012-0039-5

Ballester-Beltrán, J., Lebourg, M., Rico, P., and Salmerón-Sánchez, M. (2015). Cell migration within confined sandwich-like nanoenvironments. Nanomedicine 10, 815-828. doi:10.2217/nnm.14.217

Ballester-Beltran, J., Lebourg, M., and Salmeron-Sanchez, M. (2013). Dorsal and ventral stimuli in sandwich-like microenvironments. Effect on cell differentiation. Biotechnol. Bioeng. 110, 3048-3058. doi:10.1002/bit.24972

Ballester-Beltrán, J., Moratal, D., Lebourg, M., and Salmerón-Sánchez, M. (2014). Fibronectin-matrix sandwich-like microenvironments to manipulate cell fate. Biomater. Sci. 2, 381-389. doi:10.1039/C3BM60248F

Balzer, E., Tong, Z., Paul, C., Hung, W. C., Stroka, K., Boggs, A., et al. (2012). Physical confinement alters tumor cell adhesion and migration phenotypes. FASEB J. 26, 4045-4056. doi:10.1096/fj.12-211441 special attention to the study of topographical cues since its ability to mimic the fibrillar structure of the ECM is key to unravel cell biology in vivo.

Novel methodologies would allow studying these surface gradients in closer $3 \mathrm{D}$ physiological environments. For example, here we have shown those offering a bi-phasic stimulation (adhesiongas, adhesion-fluid flow, and adhesion-adhesion). These technical strategies could be combined with $2 \mathrm{D}$ gradients on both dorsal and ventral sides, in order to investigate $3 \mathrm{D}$ environments-like e.g., topographical gradients on a $2 \mathrm{D}$ ventral substrate and fluid flow through the $z$ axis. These studies would set up the basis to answer complex biological questions as well as new methods to mimic the micro/nano pathological surroundings and drug assessment.

\section{Acknowledgments}

This work was supported by MRC grant MR/L022710/1 "synergistic microenvironments for non-union bone defects."

Bartneck, M., Schulte, V. A., Paul, N. E., Diez, M., Lensen, M. C., and ZwadloKlarwasser, G. (2010). Induction of specific macrophage subtypes by defined micro-patterned structures. Acta Biomater. 6, 3864-3872. doi:10.1016/j.actbio. 2010.04.025

Beningo, K. A., Dembo, M., and Wang, Y. L. (2004). Responses of fibroblasts to anchorage of dorsal extracellular matrix receptors. Proc. Natl. Acad. Sci. U.S.A. 101, 18024-18029. doi:10.1073/pnas.0405747102

Bergert, M., Chandradoss, S., Desai, R., and Paluch, E. (2012). Cell mechanics control rapid transitions between blebs and lamellipodia during migration. Proc. Natl. Acad. Sci. U.S.A. 109, 14434-14439. doi:10.1073/pnas. 1207968109

Bhattacharyya, S. P., Mekori, Y. A., Hoh, D., Paolini, R., Metcalfe, D. D., and Bianchine, P. J. (1999). Both adhesion to immobilized vitronectin and FcepsilonRI cross-linking cause enhanced focal adhesion kinase phosphorylation in murine mast cells. Immunology 98, 357-362. doi:10.1046/j.1365-2567.1999. 00883.x

Bi, Y. A., Kazolias, D., and Duignan, D. B. (2006). Use of cryopreserved human hepatocytes in sandwich culture to measure hepatobiliary transport. Drug Metab. Dispos. 34, 1658-1665. doi:10.1124/dmd.105.009118

Biggs, M. J., Richards, R., Gadegaard, N., McMurray, R., Affrossman, S., Wilkinson, C., et al. (2009a). Interactions with nanoscale topography: adhesion quantification and signal transduction in cells of osteogenic and multipotent lineage. $J$. Biomed. Mater. Res. A 91, 195-208. doi:10.1002/jbm.a.32196

Biggs, M. J., Richards, R. G., Gadegaard, N., Wilkinson, C. D. W., Oreffo, R. O. C., and Dalby, M. J. (2009b). The use of nanoscale topography to modulate the dynamics of adhesion formation in primary osteoblasts and ERK/MAPK signalling in STRO-1+ enriched skeletal stem cells. Biomaterials 30, 5094-5103. doi:10.1016/j.biomaterials.2009.05.049

Biggs, M. J., Richards, R. G., and Dalby, M. J. (2010). Nanotopographical modification: a regulator of cellular function through focal adhesions. Nanomedicine 6, 619-633. doi:10.1016/j.nano.2010.01.009

Biggs, M. J., Richards, R. G., McFarlane, S., Wilkinson, C. D., Oreffo, R. O., and Dalby, M. J. (2008). Adhesion formation of primary human osteoblasts and the functional response of mesenchymal stem cells to $330 \mathrm{~nm}$ deep microgrooves. J. R. Soc. Interface 5, 1231-1242. doi:10.1002/jbm.a.32196

Cassidy, J. W., Roberts, J. N., Smith, C. A., Robertson, M., White, K., Biggs, M. J., et al. (2014). Osteogenic lineage restriction by osteoprogenitors cultured on nanometric grooved surfaces: the role of focal adhesion maturation. Acta Biomater. 10, 651-660. doi:10.1016/j.actbio.2013.11.008

Charras, G., and Paluch, E. (2008). Blebs lead the way: how to migrate without lamellipodia. Nature 9, 730-736. doi:10.1038/nrm 2453

Charras, G., and Sahai, E. (2014). Physical influence of the extracellular environment on cell migration. Nat. Rev. 15, 813-824. doi:10.1038/nrm3897 
Chaudhuri, O., Parekh, S. H., Lam, W. A., and Fletcher, D. A. (2009). Combined atomic force microscopy and side-view optical imaging for mechanical studies of cells. Nat. Methods 6, 383-387. doi:10.1038/nmeth.1320

Chua, J. S., Chng, C. P., Moe, A. A., Tann, J. Y., Goh, E. L., Chiam, K. H., et al. (2014). Extending neurites sense the depth of the underlying topography during neuronal differentiation and contact guidance. Biomaterials 35, 7750-7761. doi:10.1016/j.biomaterials.2014.06.008

Clark, P., Connolly, P., Curtis, A. S., Dow, J. A., and Wilkinson, C. D. (1990). Topographical control of cell behaviour: II. Multiple grooved substrata. Development 108, 635-644.

Cohen-Hillel, E., Mintz, R., Meshel, T., Garty, B. Z., and Ben-Baruch, A. (2009). Cell migration to the chemokine CXCL8: paxillin is activated and regulates adhesion and cell motility. Cell. Mol. Life Sci. 66, 884-899. doi:10.1007/ s00018-009-8447-5

Cowin, S. C., and Weinbaum, S. (1998). Strain amplification in the bone mechanosensory system. Am. J. Med. Sci. 316, 184-188. doi:10.1097/ 00000441-199809000-00006

Crouch, A. S., Miller, D., Luebke, K. J., and Hu, W. (2009). Correlation of anisotropic cell behaviors with topographic aspect ratio. Biomaterials 30, 1560-1567. doi:10. 1016/j.biomaterials.2008.11.041

Curtis, A., and Wilkinson, C. (1997). Topographical control of cells. Biomaterials 18, 1573-1583. doi:10.1016/S0142-9612(97)00144-0

Dalby, M. J., Gadegaard, N., Tare, R., Andar, A., Riehle, M., Herzyk, P., et al. (2007). The control of human mesenchymal cell differentiation using nanoscale symmetry and disorder. Nat. Mater. 6, 997-1003. doi:10.1038/nmat2013

Dalby, M. J., McCloy, D., Robertson, M., Wilkinson, C. D., and Oreffo, R. O. (2006). Osteoprogenitor response to defined topographies with nanoscale depths. Biomaterials 27, 1306-1315. doi:10.1016/j.biomaterials.2005.08.028

Dalby, M. J., Riehle, M. O., Yarwood, S. J., Wilkinson, C. D., and Curtis, A. S. (2003). Nucleus alignment and cell signaling in fibroblasts: response to a micro-grooved topography. Exp. Cell Res. 284, 274-282. doi:10.1016/S0014-4827(02)00053-8

De Borja Callejas, F., Martinez-Anton, A., Alobid, I., Fuentes, M., Cortijo, J., Picado, C., et al. (2014). Reconstituted human upper airway epithelium as 3-d in vitro model for nasal polyposis. PLoS ONE 9:e100537. doi:10.1371/journal. pone.0100537

De Luca, A. C., Zink, M., Weidt, A., Mayr, S. G., and Markaki, A. E. (2015). Effect of microgrooved surface topography on osteoblast maturation and protein adsorption. J. Biomed. Mater. Res. A. doi:10.1002/jbm.a.35407

DeSimone, D. W., and Horwitz, A. R. (2014). Many modes of motility. Science 345, 1002-1003. doi:10.1126/science.1259176

Diehl, K. A., Foley, J. D., Nealey, P. F., and Murphy, C. J. (2005). Nanoscale topography modulates corneal epithelial cell migration. J. Biomed. Mater. Res. A 75, 603-611. doi:10.1002/jbm.a.30467

Dunn, J. C., Tompkins, R. G., and Yarmush, M. L. (1992). Hepatocytes in collagen sandwich: evidence for transcriptional and translational regulation. J. Cell Biol. 116, 1043-1053. doi:10.1083/jcb.116.4.1043

Ebara, M., Uto, K., Idota, N., Hoffman, J. M., and Aoyagi, T. (2014). The taming of the cell: shape-memory nanopatterns direct cell orientation. Int. J. Nanomedicine 9(Suppl. 1), 117-126. doi:10.2147/IJN.S50677

Fackler, O., and Grosse, R. (2008). Cell motility through plasma membrane blebbing. J. Cell Biol. 181, 879-884. doi:10.1083/jcb.200802081

Farahani, E., Patra, H. K., Jangamreddy, J. R., Rashedi, I., Kawalec, M., Rao Pariti, R. K., et al. (2014). Cell adhesion molecules and their relation to (cancer) cell stemness. Carcinogenesis 35, 747-759. doi:10.1093/carcin/bgu045

Fernandez-Yague, M. A., Abbah, S. A., McNamara, L., Zeugolis, D. I., Pandit, A., and Biggs, M. J. (2014). Biomimetic approaches in bone tissue engineering: integrating biological and physicomechanical strategies. Adv. Drug Deliv. Rev. doi:10.1016/j.addr.2014.09.005

Friedl, P., Wolf, K., and Lammerding, J. (2011). Nuclear mechanics during cell migration. Curr. Opin. Cell Biol. 23, 55-64. doi:10.1016/j.ceb.2010.10.015

Fuentes, D. E., Bae, C., and Butler, P. J. (2011). Focal adhesion induction at the tip of a functionalized nanoelectrode. Cell. Mol. Bioeng. 4, 616-626. doi:10.1007/ s12195-011-0214-7

Fujita, S., Ohshima, M., and Iwata, H. (2009). Time-lapse observation of cell alignment on nanogrooved patterns. J. R. Soc. Interface 6(Suppl. 3), S269-S277. doi:10.1098/rsif.2008.0428.focus

Gaharwar, A. K., Nikkhah, M., Sant, S., and Khademhosseini, A. (2014). Anisotropic poly (glycerol sebacate)-poly ( $\varepsilon$-caprolactone) electrospun fibers promote endothelial cell guidance. Biofabrication 7, 015001. doi:10.1088/1758-5090/7/1/ 015001
Gamboa, J. R., Mohandes, S., Tran, P. L., Slepian, M. J., and Yoon, J. Y. (2013). Linear fibroblast alignment on sinusoidal wave micropatterns. Colloids Surf. B Biointerfaces 104, 318-325. doi:10.1016/j.colsurfb.2012.11.035

Garland, S. P., McKee, C. T., Chang, Y. R., Raghunathan, V. K., Russell, P., and Murphy, C. J. (2014). A cell culture substrate with biologically relevant sizescale topography and compliance of the basement membrane. Langmuir 30, 2101-2108. doi:10.1021/la403590v

Gattazzo, F., Urciuolo, A., and Bonaldo, P. (2014). Extracellular matrix: a dynamic microenvironment for stem cell niche. Biochim. Biophys. Acta 1840, 2506-2519. doi:10.1016/j.bbagen.2014.01.010

Germanier, Y., Tosatti, S., Broggini, N., Textor, M., and Buser, D. (2006). Enhanced bone apposition around biofunctionalized sandblasted and acid-etched titanium implant surfaces - a histomorphometric study in miniature pigs. Clin. Oral Implants Res. 17, 251-257. doi:10.1111/j.1600-0501.2005.01222.x

Gong, T., Zhao, K., Yang, G., Li, J., Chen, H., Chen, Y., et al. (2014). The control of mesenchymal stem cell differentiation using dynamically tunable surface microgrooves. Adv. Healthc. Mater. 3, 1608-1619. doi:10.1002/adhm.201300692

Hanein, D., and Horwitz, A. (2012). The structure of cell-matrix adhesions: the new frontier. Curr. Opin. Cell Biol. 24, 134-140. doi:10.1016/j.ceb.2011.12.001

Harimoto, M., Yamato, M., Hirose, M., Takahashi, C., Isoi, Y., Kikuchi, A., et al. (2002). Novel approach for achieving double-layered cell sheets co-culture: overlaying endothelial cell sheets onto monolayer hepatocytes utilizing temperatureresponsive culture dishes. J Biomed Mater Res 62, 464-470. doi:10.1002/jbm. 10228

Harrison, R. (1911). On the stereotropism of embryonic cells. Science 34, 279-281. doi:10.1126/science.34.870.279

Herrero-Climent, M., Lazaro, P., Rios, J. V., Lluch, S., Marques, M., Guillem-Marti, J., et al. (2013). Influence of acid-etching after grit-blasted on osseointegration of titanium dental implants: in vitro and in vivo studies. J. Mater. Sci. Mater. Med. 24, 2047-2055. doi:10.1007/s10856-013-4935-0

Hocde, S. A., Hyrien, O., and Waugh, R. E. (2009). Cell adhesion molecule distribution relative to neutrophil surface topography assessed by TIRFM. Biophys. J. 97, 379-387. doi:10.1016/j.bpj.2009.04.035

Huang, H., Nakayama, Y., Qin, K., Yamamoto, K., Ando, J., Yamashita, J., et al. (2005). Differentiation from embryonic stem cells to vascular wall cells under in vitro pulsatile flow loading. J. Artif. Organs 8, 110-118. doi:10.1007/ s10047-005-0291-2

Ishibazawa, A., Nagaoka, T., Takahashi, T., Yamamoto, K., Kamiya, A., Ando, J., et al. (2011). Effects of shear stress on the gene expressions of endothelial nitric oxide synthase, endothelin-1, and thrombomodulin in human retinal microvascular endothelial cells. Invest. Ophthalmol. Vis. Sci. 52, 8496-8504. doi:10.1167/iovs.11-7686

Itala, A., Koort, J., Ylanen, H. O., Hupa, M., and Aro, H. T. (2003). Biologic significance of surface microroughing in bone incorporation or porous bioactive glass implants. J. Biomed. Mater. Res. A 67A, 496-503. doi:10.1002/jbm.a.10501

Janson, I. A., Kong, Y. P., and Putnam, A. J. (2014). Nanotopographic substrates of poly (methyl methacrylate) do not strongly influence the osteogenic phenotype of mesenchymal stem cells in vitro. PLOS ONE 9:e90719. doi:10.1371/journal. pone.0090719

Jeon, K. J., Park, S. H., Shin, J. W., Kang, Y. G., Hyun, J. S., Oh, M. J., et al. (2014). Combined effects of flow-induced shear stress and micropatterned surface morphology on neuronal differentiation of human mesenchymal stem cells. J. Biosci. Bioeng. 117, 242-247. doi:10.1016/j.jbiosc.2013.08.002

Jia, Y. Y., Li, F., Geng, N., Gong, P., Huang, S. J., Meng, L. X., et al. (2014). Fluid flow modulates the expression of genes involved in the Wnt signaling pathway in osteoblasts in 3D culture conditions. Int. J. Mol. Med. 33, 1282-1288. doi:10.3892/ijmm.2014.1694

Kasorn, A., Alcaide, P., Jia, Y., Subramanian, K. K., Sarraj, B., Li, Y., et al. (2009). Focal adhesion kinase regulates pathogen-killing capability and life span of neutrophils via mediating both adhesion-dependent and -independent cellular signals. J. Immunol. 183, 1032-1043. doi:10.4049/jimmunol.0802984

Kim, J., Bae, W. G., Choung, H. W., Lim, K. T., Seonwoo, H., Jeong, H. E., et al. (2014a). Multiscale patterned transplantable stem cell patches for bone tissue regeneration. Biomaterials 35, 9058-9067. doi:10.1016/j.biomaterials.2014.07. 036

Kim, J. S., Klosener, J., Flor, S., Peters, T. M., Ludewig, G., Thorne, P. S., et al. (2014b). Toxicity assessment of air-delivered particle-bound polybrominated diphenyl ethers. Toxicology 317, 31-39. doi:10.1016/j.tox.2014.01.005

Kim, J., Kim, H. N., Lim, K. T., Kim, Y., Seonwoo, H., Park, S. H., et al. (2013). Designing nanotopographical density of extracellular matrix for controlled 
morphology and function of human mesenchymal stem cells. Sci. Rep. 3, 3552. doi:10.1038/srep03552

Kim, S. S., Wen, W., Prowse, P., and Hamilton, D. W. (2015). Regulation of matrix remodelling phenotype in gingival fibroblasts by substratum topography. J. Cell. Mol. Med. doi:10.1111/jcmm.12451

Kim, Y., and Rajagopalan, P. (2010). 3D hepatic cultures simultaneously maintain primary hepatocyte and liver sinusoidal endothelial cell phenotypes. PLoS ONE 5:e15456. doi:10.1371/journal.pone.0015456

Knothe Tate, M. L., Knothe, U., and Niederer, P. (1998). Experimental elucidation of mechanical load-induced fluid flow and its potential role in bone metabolism and functional adaptation. Am. J. Med. Sci. 316, 189-195. doi:10. 1097/00000441-199809000-00007

Knothe Tate, M. L., Steck, R., Forwood, M. R., and Niederer, P. (2000). In vivo demonstration of load-induced fluid flow in the rat tibia and its potential implications for processes associated with functional adaptation. J. Exp. Biol. 203, 2737-2745.

Kooter, I.M., Alblas, M.J., Jedynska, A.D., Steenhof, M., Houtzager, M.M., Van Ras, M. (2013). Alveolar epithelial cells (A549) exposed at the air-liquid interface to diesel exhaust: First study in TNO's powertrain test center. Toxicol In Vitro 27, 2342-2349. doi:10.1016/j.tiv.2013.10.007

Kwon, K. W., Park, H., Song, K. H., Choi, J. C., Ahn, H., Park, M. J., et al. (2012). Nanotopography-guided migration of T cells. J. Immunol. 189, 2266-2273. doi:10.4049/jimmunol.1102273

Leal-Egaña, A., Díaz-Cuenca, A., and Boccaccini, A. (2013). Tuning of cellbiomaterial anchorage for tissue regeneration. Adv. Mater. Weinheim 25, 4049-4057. doi:10.1002/adma.201301227

Lee, V. K., Lanzi, A. M., Haygan, N., Yoo, S. S., Vincent, P. A., and Dai, G. (2014). Generation of multi-scale vascular network system within 3D hydrogel using 3D bio-printing technology. Cell. Mol. Bioeng. 7, 460-472. doi:10.1007/ s12195-014-0340-0

Lenhert, S., Meier, M. B., Meyer, U., Chi, L., and Wiesmann, H. P. (2005). Osteoblast alignment, elongation and migration on grooved polystyrene surfaces patterned by Langmuir-Blodgett lithography. Biomaterials 26, 563-570. doi:10.1016/j. biomaterials.2004.02.068

Lim, K. T., Kim, J., Seonwoo, H., Chang, J. U., Choi, H., Hexiu, J., et al. (2013). Enhanced osteogenesis of human alveolar bone-derived mesenchymal stem cells for tooth tissue engineering using fluid shear stress in a rocking culture method. Tissue Eng. Part C Methods 19, 128-145. doi:10.1089/ten.tec.2012.0017

Lindner, V., Lappi, D. A., Baird, A., Majack, R. A., and Reidy, M. A. (1991). Role of basic fibroblast growth factor in vascular lesion formation. Circ. Res. 68, 106-113. doi:10.1161/01.RES.68.1.106

Londono, C., Loureiro, M. J., Slater, B., Lucker, P. B., Soleas, J., Sathananthan, S., et al. (2014). Nonautonomous contact guidance signaling during collective cell migration. Proc. Natl. Acad. Sci. U.S.A. 111, 1807-1812. doi:10.1073/pnas. 1321852111

Losert, W., Driscoll, M., Guven, C., Sun, X. Y., and Fourkas, J. (2013). Cellular contact guidance through dynamic sensing of surface topography. Biophys. J. 104, 148A-148A. doi:10.1016/j.bpj.2012.11.840

Marino, A., Ciofani, G., Filippeschi, C., Pellegrino, M., Pellegrini, M., Orsini, P., et al. (2013). Two-photon polymerization of sub-micrometric patterned surfaces: investigation of cell-substrate interactions and improved differentiation of neuron-like cells. ACS Appl. Mater. Interfaces 5, 13012-13021. doi:10.1021/ am403895k

McKee, C. T., Raghunathan, V. K., Nealey, P. F., Russell, P., and Murphy, C. J. (2011). Topographic modulation of the orientation and shape of cell nuclei and their influence on the measured elastic modulus of epithelial cells. Biophys. J. 101, 2139-2146. doi:10.1016/j.bpj.2011.09.042

McMurray, R. J., Wann, A. K. T., Thompson, C. L., Connelly, J. T., and Knight, M. M. (2013). Surface topography regulates wnt signaling through control of primary cilia structure in mesenchymal stem cells. Sci. Rep. 3, 3545. doi:10.1038/ srep03545

McNamara, L. E., Sjöström, T., Burgess, K. E., Kim, J. J., Liu, E., Gordonov, S., et al. (2011). Skeletal stem cell physiology on functionally distinct titania nanotopographies. Biomaterials 32, 7403-7410. doi:10.1016/j.biomaterials.2011.06. 063

Metallo, C. M., Vodyanik, M. A., de Pablo, J. J., Slukvin, I. I., and Palecek, S. P. (2008). The response of human embryonic stem cell-derived endothelial cells to shear stress. Biotechnol. Bioeng. 100, 830-837. doi:10.1002/bit.21809
Nadeem, D., Sjostrom, T., Wilkinson, A., Smith, C. A., Oreffo, R. O., Dalby, M. J., et al. (2013). Embossing of micropatterned ceramics and their cellular response. J. Biomed. Mater. Res. A 101, 3247-3255. doi:10.1002/jbm.a.34622

Olivares-Navarrete, R., Hyzy, S. L., Haithcock, D. A., Cundiff, C. A., Schwartz, Z., and Boyan, B. D. (2015). Coordinated regulation of mesenchymal stem cell differentiation on microstructured titanium surfaces by endogenous bone morphogenetic proteins. Bone 73, 208-216. doi:10.1016/j.bone.2014.12 057

Paluch, E., and Raz, E. (2013). The role and regulation of blebs in cell migration. Curr. Opin. Cell Biol. 25, 582-590. doi:10.1016/j.ceb.2013.05.005

Papadaki, M., Tilton, R. G., Eskin, S. G., and McIntire, L. V. (1998). Nitric oxide production by cultured human aortic smooth muscle cells: stimulation by fluid flow. Am. J. Physiol. 274, H616-H626.

Papadopoulos, M., and Saadoun, S. (2014). Key roles of aquaporins in tumor biology. Biochim. Biophys. Acta. doi:10.1016/j.bbamem.2014.09.001

Pedron, S., Becka, E., and Harley, B. A. (2015). Spatially gradated hydrogel platform as a 3D engineered tumor microenvironment. Adv. Mater. 27, 1567-1572. doi:10.1002/adma.201404896

Peng, P., Shi, T., Liao, G., and Tang, Z. (2010). Combined AFM nano-machining and reactive ion etching to fabricate high aspect ratio structures. J. Nanosci. Nanotechnol. 10, 7287-7290. doi:10.1166/jnn.2010.2858

Perez-Garnes, M., Gonzalez-Garcia, C., Moratal, D., Rico, P., and SalmeronSanchez, M. (2011). Fibronectin distribution on demixed nanoscale topographies. Int. J. Artif. Organs 34, 54-63. doi:10.5301/IJAO.2011.6316

Petrie, R., Koo, H., and Yamada, K. (2014). Generation of compartmentalized pressure by a nuclear piston governs cell motility in a 3D matrix. Science 345, 1062-1065. doi:10.1126/science. 1256965

Petrie, R., and Yamada, K. (2012). At the leading edge of three-dimensional cell migration. J. Cell Sci. 125, 5917-5926. doi:10.1242/jcs.093732

Piekarski, K., and Munro, M. (1977). Transport mechanism operating between blood supply and osteocytes in long bones. Nature 269, 80-82. doi:10.1038/ 269080a0

Potter, C. M., Lao, K. H., Zeng, L., and Xu, Q. (2014). Role of biomechanical forces in stem cell vascular lineage differentiation. Arterioscler. Thromb. Vasc. Biol. 34, 2184-2190. doi:10.1161/ATVBAHA.114.303423

Ranganathan, S. I., Ostoja-Starzewski, M., and Ferrari, M. (2011). Quantifying the anisotropy in biological materials. J. Appl. Mech. Trans. ASME 78, 064501-1-064501-4. doi:10.1115/1.4004553

Ridley, A., Schwartz, M., Burridge, K., Firtel, R., Ginsberg, M., Borisy, G., et al. (2003). Cell migration: integrating signals from front to back. Science 302, 1704-1709. doi:10.1126/science.1092053

Sant, S., Hancock, M. J., Donnelly, J. P., Iyer, D., and Khademhosseini, A. (2010). Biomimetic gradient hydrogels for tissue engineering. Can. J. Chem. Eng. 88, 899-911. doi:10.1002/cjce.20411

Sjöström, T., McNamara, L. E., Meek, R. M., Dalby, M. J., and Su, B. (2013). 2D and 3D nanopatterning of titanium for enhancing osteoinduction of stem cells at implant surfaces. Adv. Healthc. Mater. 2, 1285-1293. doi:10.1002/adhm. 201200353

Sjöström, T., McNamara, L. E., Yang, L., Dalby, M. J., and Su, B. (2012). Novel anodization technique using a block copolymer template for nanopatterning of titanium implant surfaces. ACS Appl. Mater. Interfaces 4, 6354-6361. doi:10. 1021/am301987e

Smalt, R., Mitchell, F. T., Howard, R. L., and Chambers, T. J. (1997). Induction of $\mathrm{NO}$ and prostaglandin $\mathrm{E} 2$ in osteoblasts by wall-shear stress but not mechanical strain. Am. J. Physiol. 273, E751-E758.

Smith, C. L. C., Thilsted, A. H., Garcia-Ortiz, C. E., Radko, I. P., Marie, R., Jeppesen, C., et al. (2014). Efficient excitation of channel plasmons in tailored, UV-lithography-defined V-grooves. Nano Lett. 14, 1659-1664. doi:10.1021/ nl5002058

Song, K. H., Kwon, K. W., Choi, J. C., Jung, J., Park, Y., Suh, K. Y., et al. (2014). T cells sense biophysical cues using lamellipodia and filopodia to optimize intraluminal path finding. Integr. Biol. (Camb.) 6, 450-459. doi:10.1039/c4ib00021h

Song, K. H., Kwon, K. W., Song, S., Suh, K. Y., and Doh, J. (2012). Dynamics of T cells on endothelial layers aligned by nanostructured surfaces. Biomaterials 33, 2007-2015. doi:10.1016/j.biomaterials.2011.12.002

Stroka, K., Jiang, H., Gu, Z., Sun, S., and Konstantopoulos, K. (2014a). Bioengineering paradigms for cell migration in confined microenvironments. Curr. Opin Cell Biol. 30, 41-51. doi:10.1016/j.ceb.2014.06.001 
Stroka, K., Jiang, H., Chen, S. H., Tong, Z., Wirtz, D., Sun, S., et al. (2014b). Water permeation drives tumor cell migration in confined microenvironments. Cell 157, 611-623. doi:10.1016/j.cell.2014.02.052

Svensson, S., Suska, F., Emanuelsson, L., Palmquist, A., Norlindh, B., Trobos, M., et al. (2013). Osseointegration of titanium with an antimicrobial nanostructured noble metal coating. Nanomedicine 9, 1048-1056. doi:10.1016/j.nano.2013.04. 009

Swift, B., Pfeifer, N. D., and Brouwer, K. L. (2010). Sandwich-cultured hepatocytes: an in vitro model to evaluate hepatobiliary transporter-based drug interactions and hepatotoxicity. Drug Metab. Rev. 42, 446-471. doi:10.3109/ 03602530903491881

Takahashi, H., Shimizu, T., Nakayama, M., Yamato, M., and Okano, T. (2013). The use of anisotropic cell sheets to control orientation during the self-organization of 3D muscle tissue. Biomaterials 34, 7372-7380. doi:10.1016/j.biomaterials. 2013.06.033

Tan, K., Tann, J., Sathe, S. R., Goh, S., Ma, D., Goh, E., et al. (2015). Enhanced differentiation of neural progenitor cells into neurons of the mesencephalic dopaminergic subtype on topographical patterns. Biomaterials 43, 32-43. doi:10. 1016/j.biomaterials.2014.11.036

Tavangar, A., Tan, B., and Venkatakrishnan, K. (2013). The influence of laserinduced 3-D titania nanofibrous platforms on cell behavior. J. Biomed. Nanotechnol. 9, 1837-1846. doi:10.1166/jbn.2013.1679

Teixeira, A. I., McKie, G. A., Foley, J. D., Bertics, P. J., Nealey, P. F., and Murphy, C. J. (2006). The effect of environmental factors on the response of human corneal epithelial cells to nanoscale substrate topography. Biomaterials 27, 3945-3954. doi:10.1016/j.biomaterials.2006.01.044

Teixeira, A. I., Nealey, P. F., and Murphy, C. J. (2004). Responses of human keratocytes to micro- and nanostructured substrates. J. Biomed. Mater. Res. A 71, 369-376. doi:10.1002/jbm.a.30089

Tonazzini, I., Cecchini, A., Elgersma, Y., and Cecchini, M. (2014). Interaction of SH-SY5Y cells with nanogratings during neuronal differentiation: comparison with primary neurons. Adv. Healthc. Mater. 3, 581-587. doi:10.1002/adhm. 201300216

Tonazzini, I., Meucci, S., Faraci, P., Beltram, F., and Cecchini, M. (2013). Neuronal differentiation on anisotropic substrates and the influence of nanotopographical noise on neurite contact guidance. Biomaterials 34, 6027-6036. doi:10.1016/j. biomaterials.2013.04.039

Tsai, H. Y., Pitera, J. W., Miyazoe, H., Bangsaruntip, S., Engelmann, S. U., Liu, C. C., et al. (2014). Two-dimensional pattern formation using graphoepitaxy of PS-bPMMA block copolymers for advanced FinFET device and circuit fabrication. ACS Nano 8, 5227-5232. doi:10.1021/nn501300b

Vicente-Manzanares, M., and Horwitz, A. (2011). Adhesion dynamics at a glance. J. Cell Sci. 124, 3923-3927. doi:10.1242/jcs.095653

Voisin, C., Aerts, C., Jakubczk, E., and Tonnel, A. B. (1977). [La culture cellulaire en phase gazeuse. Un nouveau modele experimental d'etude in vitro des activites des macrophages alveolaires]. Bull. Eur. Physiopathol. Respir. 13, 69-82.

Vozzi, F., Bianchi, F., Ahluwalia, A., and Domenici, C. (2014). Hydrostatic pressure and shear stress affect endothelin-1 and nitric oxide release by endothelial cells in bioreactors. Biotechnol. J. 9, 146-154. doi:10.1002/biot.201300016

Wang, P. Y., Li, W. T., Yu, J., and Tsai, W. B. (2012). Modulation of osteogenic, adipogenic and myogenic differentiation of mesenchymal stem cells by submicron grooved topography. J. Mater. Sci. Mater. Med. 23, 3015-3028. doi:10.1007/ s10856-012-4748-6

Wang, Y., Jiang, S., Shi, H., Zhang, W., Qiao, J., Wu, M., et al. (2013a). Heteroepitaxy of anisotropic polycaprolactone films for the guidance of smooth muscle cell growth. Chem. Commun. 49, 10421-10423. doi:10.1039/C3CC46359A

Wang, Z. Y., Teo, E. Y., Chong, M. S., Zhang, Q. Y., Lim, J., Zhang, Z. Y., et al. (2013b). Biomimetic three-dimensional anisotropic geometries by uniaxial stretch of poly( $\varepsilon$-caprolactone) films for mesenchymal stem cell proliferation, alignment, and myogenic differentiation. Tissue Eng. Part C Methods 19, 538-549. doi:10.1089/ten.tec.2012.0472

Watari, S., Hayashi, K., Wood, J., Russell, P., Nealey, P., Murphy, C., et al. (2012). Modulation of osteogenic differentiation in hMSCs cells by submicron topographically-patterned ridges and grooves. Biomaterials 33, 128-136. doi:10. 1016/j.biomaterials.2011.09.058
Weiss, P., and Garber, B. (1952). Shape and movement of mesenchyme cells as functions of the physical structure of the medium. Proc. Natl. Acad. Sci. U.S.A. 38, 264-280. doi:10.1073/pnas.38.3.264

Wilson, K., Lewalle, A., Fritzsche, M., Thorogate, R., Duke, T., and Charras, G. (2013). Mechanisms of leading edge protrusion in interstitial migration. Nat. Commun. 4, 289. doi:10.1038/ncomms3896

Wojciak, B., Crossan, J., Curtis, A., and Wilkinson, C. (1995). Grooved substrata facilitate in vitro healing of completely divided flexor tendons. J. Mater. Sci. Mater. Med. 6, 266-271. doi:10.1007/BF00120269

$\mathrm{Wu}, \mathrm{X}$., and Wang, S. (2013). Biomimetic calcium carbonate concentric microgrooves with tunable widths for promoting MC3T3-E1 cell functions. Adv. Healthc. Mater. 2, 326-333. doi:10.1002/adhm.201200205

Wu, Y. N., Law, J. B. K., He, A. Y., Low, H. Y., Hui, J. H. P., Lim, C. T., et al. (2014). Substrate topography determines the fate of chondrogenesis from human mesenchymal stem cells resulting in specific cartilage phenotype formation. Nanomedicine 10, 1507-1516. doi:10.1016/j.nano.2014.04.002

Xia, L., Arooz, T., Zhang, S., Tuo, X., Xiao, G., Susanto, T. A., et al. (2012a). Hepatocyte function within a stacked double sandwich culture plate cylindrical bioreactor for bioartificial liver system. Biomaterials 33, 7925-7932. doi:10.1016/ j.biomaterials.2012.06.078

Xia, L., Feng, B., Wang, P., Ding, S., Liu, Z., Zhou, J., et al. (2012b). In vitro and in vivo studies of surface-structured implants for bone formation. Int. J. Nanomedicine 7, 4873-4881. doi:10.2147/IJN.S29496

Xia, L., Ng, S., Han, R., Tuo, X., Xiao, G., Leo, H. L., et al. (2009). Laminarflow immediate-overlay hepatocyte sandwich perfusion system for drug hepatotoxicity testing. Biomaterials 30, 5927-5936. doi:10.1016/j.biomaterials.2009. 07.022

Xie, L., Liao, X., Yin, G., Huang, Z., Yan, D., Yao, Y., et al. (2011). Preparation, characterization, in vitro bioactivity, and osteoblast adhesion of multi-level porous titania layer on titanium by two-step anodization treatment. J. Biomed. Mater. Res. A 98, 312-320. doi:10.1002/jbm.a.33120

Yang, K., Jung, H., Lee, H. R., Lee, J. S., Kim, S. R., Song, K. Y., et al. (2014) Multiscale, hierarchically patterned topography for directing human neural stem cells into functional neurons. ACS Nano 8, 7809-7822. doi:10.1021/ Nn501182f

Yang, Y., Kusano, K., Frei, H., Rossi, F., Brunette, D. M., and Putnins, E. E. (2010). Microtopographical regulation of adult bone marrow progenitor cells chondrogenic and osteogenic gene and protein expressions. J. Biomed. Mater. Res. A 95, 294-304. doi:10.1002/jbm.a.32838

Yim, E. K., Pang, S. W., and Leong, K. W. (2007). Synthetic nanostructures inducing differentiation of human mesenchymal stem cells into neuronal lineage. Exp. Cell Res. 313, 1820-1829. doi:10.1016/j.yexcr.2007.02.031

Zamora, P.O., Benson, J.M., Li, A.P., Brooks, A.L. (1983). Evaluation of an exposure system using cells grown on collagen gels for detecting highly volatile mutagens in the CHO/HGPRT mutation assay. Environ Mutagen 5, 795-801.

Zamora, P.O., Gregory, R.E., Li, A.P., Brooks, A.L. (1986). An in vitro model for the exposure of lung alveolar epithelial cells to toxic gases. J Environ Pathol Toxicol Oncol 7, 159-168.

Zhu, B., Lu, Q., Yin, J., Hu, J., and Wang, Z. (2005). Alignment of osteoblast-like cells and cell-produced collagen matrix induced by nanogrooves. Tissue Eng. 11, 825-834. doi:10.1089/ten.2005.11.825

Zhu, J., Li, J., Wang, B., Zhang, W. J., Zhou, G., Cao, Y., et al. (2010). The regulation of phenotype of cultured tenocytes by microgrooved surface structure. Biomaterials 31, 6952-6958. doi:10.1016/j.biomaterials.2010.05.058

Conflict of Interest Statement: The authors declare that the research was conducted in the absence of any commercial or financial relationships that could be construed as a potential conflict of interest. The Review Editor Dimitrios I. Zeugolis declares that, despite being affiliated to the same institution as author Manus J. P. Biggs, the review process was handled objectively and no conflict of interest exists.

Copyright (C) 2015 Ballester-Beltrán, Biggs, Dalby, Salmerón-Sánchez and Leal-Egaña. This is an open-access article distributed under the terms of the Creative Commons Attribution License (CC BY). The use, distribution or reproduction in other forums is permitted, provided the original author(s) or licensor are credited and that the original publication in this journal is cited, in accordance with accepted academic practice. No use, distribution or reproduction is permitted which does not comply with these terms. 